\title{
Phytoplankton niches, traits and eco-evolutionary responses to global environmental change
}

\author{
Elena Litchman ${ }^{1,2, *}$, Kyle F. Edwards ${ }^{1}$, Christopher A. Klausmeier ${ }^{1,2}$, \\ Mridul K. Thomas ${ }^{1}$ \\ ${ }^{1}$ Michigan State University, Kellogg Biological Station, Hickory Corners, Michigan 49060, USA \\ ${ }^{2}$ Centre for Ocean Life and Section of Ocean Ecology and Climate, DTU Aqua, 2920 Charlottenlund, Denmark
}

\begin{abstract}
Phytoplankton are major primary producers in aquatic ecosystems and are sensitive to various aspects of global environmental change. They can respond through phenotypic plasticity, species sorting, genetic adaptation, or a combination of these processes. Here we present conceptual, experimental and theoretical ways to predict different phytoplankton responses to global change. Using phytoplankton ecological niches to predict their responses to multiple environmental stressors is a promising new approach. Functional traits of phytoplankton, such as resource utilization traits and tolerance curves for various environmental factors like temperature, can be used to define niches along major axes. Characterization of pairwise and higher dimension trade-offs among traits should help predict possible niche changes along multiple dimensions simultaneously. The potential for evolutionary responses to global change can be assessed using evolution experiments with individual strains, as well as in communities, because the responses may depend on the presence of competitors, grazers, and parasites. The evolutionary pressures induced by multiple stressors may have interactive effects and, thus, should be investigated simultaneously. Novel models of trait evolution in a community context should provide additional insights into potential adaptation trajectories under diverse global change scenarios.
\end{abstract}

KEY WORDS: Ecological niche $\cdot$ Climate change $\cdot$ Trait-based approach $\cdot$ Trade-off $\cdot$ Experimental evolution $\cdot$ Community $\cdot$ Adaptive dynamics

\section{INTRODUCTION}

Phytoplankton are responsible for about half the global primary productivity, play a major role in most biogeochemical cycles, and form the basis of many aquatic food webs (Field et al. 1998, Falkowski et al. 2008). The contribution to major elemental cycles differs greatly between the major functional groups of phytoplankton. Processes such as nitrogen fixation, calcium uptake, and silicon uptake occur almost solely in single groups, in these cases the cyanobacteria, coccolithophorids, and diatoms. Some taxa, such as the cyanobacterium Trichodesmium sp. and the dimethyl sulfide-producing coccolithophorid Emiliania huxleyi, are believed to exert regional and possibly global effects (Brown \& Yoder 1994, Staal et al. 2003). Phytoplankton are extremely sensitive to global environmental change, responding not only through total biomass but community composition as well (Li et al. 2009). In order to understand global elemental cycles and predict the climate change-driven alterations to them, it would be valuable to understand patterns in community structure and productivity of major phytoplankton taxa.

Predicting how phytoplankton communities will reorganize in the future in response to changes in climate and other global change stressors is, therefore, a major challenge facing oceanographers, aquatic ecologists, and environmental scientists. Will the biomass of phytoplankton decline or increase in the 
future? What taxonomic groups and individual species could benefit or be hit especially hard by changing environmental conditions? Answers to these questions will be required if we want to understand how oceanic ecosystems will function in the future.

Organisms can respond to changing environmental conditions in 3 distinct ways that we briefly outline here (Fig. 1). First, a species' phenotypic plasticity (Table 1) can allow it to persist as the environment changes (Charmantier et al. 2008), essentially widening its ecological niche (Polechova \& Storch 2008). Species, as well as traits, differ in their plasticity ranges, and higher plasticity is often (but not always) beneficial for persisting under global change (Nicotra et al. 2010). Second, if the limits of phenotypic plasticity of individual species are reached, species sorting (replacement) may occur as a response to changing environmental conditions (Ackerly 2003). Species that are better adapted to novel conditions will increase in abundance, competitively displacing more poorly adapted species. Such species may already be present in a community or may arrive via immigration (Urban et al. 2011). Finally, species may also genetically adapt to changing conditions, via clonal selection or selection on new genotypes arising through mutation, horizontal gene transfer, or recombination.

Therefore, phenotypic plasticity, species sorting, and genetic adaptation can all contribute to species responses to global environmental change and can act simultaneously or sequentially. It is, however, extremely difficult to predict or determine in retrospect the relative importance of individual pro- cesses. Further complications arise because environmental changes are multidimensional and responses may be both nonlinear and nonadditive. A promising approach to dealing with this complexity and increasing our mechanistic understanding of the effects of multiple stressors is to quantitatively define multidimensional ecological niches of phytoplankton and determine the influences of environmental conditions on niches of individual species and functional groups. As we describe below, mechanistic approaches to the niche have the potential to unify our understanding of how communities respond to global change via phenotypic plasticity (e.g. thermal tolerance curves), genetic change (e.g. selection on intraspecific variation in thermal tolerance curves), and species sorting (e.g. sorting due to interspecific variation in thermal tolerance curves). Furthermore, characterizing multidimensional niche space for individual species or functional groups could help predict phytoplankton responses to diverse global change stressors acting simultaneously. By constructing trait-based eco-evolutionary models informed by these data it will be possible to make short-term and long-term predictions as to how communities will respond via multiple mechanisms to multiple stressors.

Here we describe the concept of the niche and how it can be made more mechanistic using functional traits of organisms, we discuss the role of traits in explaining present and future community structure and dynamics, and we suggest theoretical and experimental ways to predict species eco-evolutionary responses to multiple environmental stressors.
A Initial state

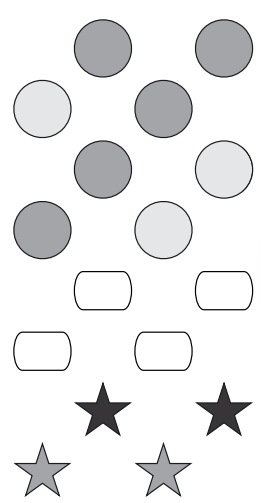

B Phenotypic plasticity
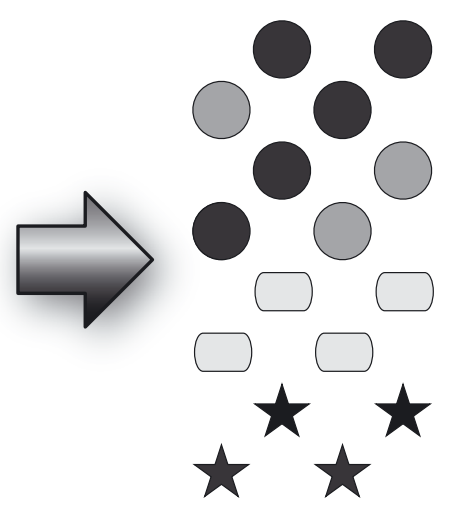

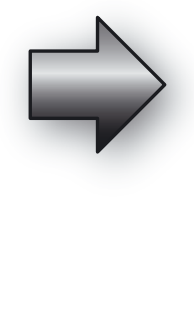

C Natural selection and species sorting

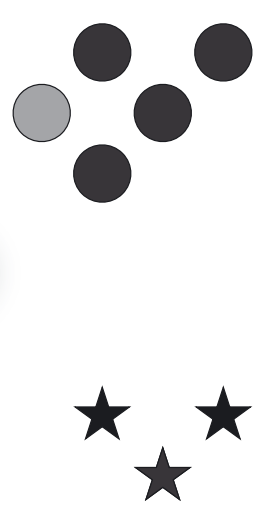

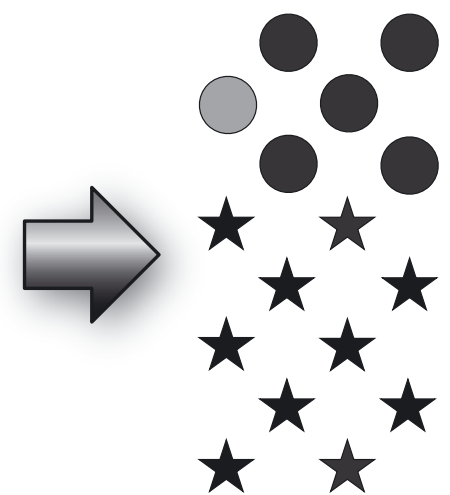

Fig. 1. Diagram of possible responses of a community to changing environment. (A) A community consists of 3 species (stars, circles, and rectangles), different shades represent different phenotypes (and potentially genotypes). (B) All species respond to changing environment by altering their phenotypic traits (phenotypic plasticity). (C) One species (rectangles) is maladapted to novel conditions and cannot persist in the community, while the best-adapted species (stars) increases in abundance more than the other persisting species (circles) (species sorting). Certain phenotypes and, potentially, genotypes (dark ones) in both species are better adapted to novel conditions and increase in frequency (natural selection) 


\section{THE NICHE CONCEPT}

The concept of the niche is one of the fundamental ideas in ecology. It was introduced by J. Grinnell and C. Elton early in the 20th century, and further developed by G. E. Hutchinson and R. MacArthur in the 1950s and 1960s, after which it fell out of favor for some time (Chase \& Leibold 2003). Since the early 2000s, the concept of the niche has been experiencing a renaissance, with multiple papers and books reinvigorating the idea (Peterson et al. 1999, Chase \& Leibold 2003), including the applications of the niche concept to predicting the effects of global change on various organisms (Wiens et al. 2009). There are several views of the niche, placing emphasis on different aspects. The niche can be considered a part of environmental space that a species can occupy, defined primarily by abiotic factors, which is sometimes called the Grinnellian niche (Wiens et al. 2009). Another view puts more emphasis on the functional role that a species or a group of species plays in an ecosystem and is referred to as the Eltonian niche (Polechova \& Storch 2008, Wiens et al. 2009). Hutchinson's idea of a niche as an $n$-dimensional hypervolume combines the 2 views (Polechova \& Storch 2008) and also defines and distinguishes the fundamental and realized niche. A fundamental niche describes the potential space along the multiple resource and environmental factor dimensions where a species can live in the absence of biotic interactions (Hutchinson 1957). A realized niche is a subset of a fundamental niche that allows species persistence in the presence of competition (original Hutchinson's definition) and other biotic interactions such as predation (Colwell \& Rangel 2009, Wiens et al. 2009).

\section{LINKING NICHES TO TRAITS}

Although the concept of the niche is very attractive, applying it to real-world questions is challenging be- cause of the difficulty in identifying all the relevant axes and determining the ranges on all those axes that lead to species persistence. These challenges may be somewhat lessened in phytoplankton, because the main niche dimensions are probably fewer and easier to identify than in other, more complex, organisms. These dimensions include resources, such as nutrients and light, as well as temperature, $\mathrm{pH}$, grazers, and parasites (Litchman et al. 2010). Once potential niche axes are known, the most commonly used way to characterize species niches is to analyze species abundances (or presence-absence) along environmental gradients and use statistical techniques to delineate the niche (Guisan \& Thuiller 2005). These approaches are often called environmental niche modeling or species distribution models (SDMs) and are now widely used in terrestrial ecology, including applications to predicting species responses to global change (Pearman et al. 2008, Thuiller et al. 2008). However, much niche modeling suffers from a lack of a clear mechanistic basis and unrealistic assumptions, such as niche conservatism and absence of biotic interactions (Pearman et al. 2008, Kearney \& Porter 2009, Wiens et al. 2009; reviewed further in the 'Niche models' section).

A possible solution to these issues is to use a species' traits to define its ecological niche (Colwell \& Rangel 2009, Wiens et al. 2009, Kearney et al. 2010). Trait-based approaches have gained popularity, especially in terrestrial plant ecology, and can help increase our mechanistic understanding of community structure and dynamics (McGill et al. 2006, Bruggeman \& Kooijman 2007, Litchman et al. 2007). Using functional traits to mechanistically define ecological niches has been proposed recently (Chase \& Leibold 2003) and applied to terrestrial ectotherms (Kearney \& Porter 2009, Kearney et al. 2010) but has not been developed for phytoplankton or other microbes. Kearney and colleagues propose 3 major frameworks to connect functional traits to ecological niches: biophysical ecology, the geometric frame-

Table 1. Main terms used in the text and their definitions

\begin{tabular}{|ll|}
\hline Term & Brief definition \\
\hline Niche & Conditions where a species' growth rate is positive \\
Genotype & Genetic makeup of an organism \\
Phenotype & Observed characteristics of an organism \\
Phenotypic plasticity & Changes in an organism's phenotype in response to changes in the environment \\
Genetic adaptation & Changes in a population's distribution of genotypes in response to changes in the environment \\
Trait & An element of an organism's phenotype \\
Functional trait & A trait that determines fitness \\
Species sorting & Changes in community composition due to interspecific interactions leading to exclusion \\
\hline
\end{tabular}


work for nutrition, and dynamic energy budget (DEB) models (Kearney et al. 2010). Similarly, Leibold and Chase (Leibold 1995, Chase \& Leibold 2003) developed mechanistic niche models by adapting the resource competition framework (Tilman 1982) to other processes that affect an organism's fitness. This approach is well suited for phytoplankton, as the resource competition theory itself was first developed for phytoplankton (Tilman 1982, Tilman et al. 1982). Furthermore, a trait-based approach based on resource competition theory mechanistically unites the Grinellian and Eltonian perspectives, because species' traits determine the conditions under which they can persist in isolation, as well as their impacts on other species in the community. This combination of requirements and impacts translates, in Hutchinson's terms, from fundamental to realized niches (Chase \& Leibold 2003). Therefore, this approach to the niche can connect traits, niches, and the biogeochemical effects of phytoplankton.

For example, if a species has certain trait values for nutrient-dependent growth and mortality, it is then possible to define a range of a given resource where the net growth rate would be positive. This range would, then, delineate the fundamental niche of the species along the axis of that resource (Fig. 2A). If resource levels are affected by competitors, this approach can define the realized niche as well, e.g. if under particular environmental conditions competitors reduce nutrient concentrations below that required for the focal species to persist $\left(R^{*} ;\right.$ Fig. $\left.2 \mathrm{~A}\right)$, then the current environmental conditions are not within that species' realized niche. Identifying traits for multiple resource- or environmental factorrelated growth would then allow us to define the ecological niche of a species in all these dimensions (Fig. 2B). Therefore, defining species trait ranges along the multiple environmental axes should help us to quantitatively describe the multidimensional niche space. As species differ in their trait values (Litchman et al. 2007, Litchman \& Klausmeier 2008), the quantitative knowledge of species traits will help determine niche differences across species, as well as the consequences of such differences for species coexistence and diversity (Chase \& Leibold 2003).

The niche perspective on species coexistence and diversity contrasts with neutral theory that assumes no meaningful differences in traits of species and, thus, in their fitness (Hubbell 2001). According to neutral theory, changes in communities may only occur due to stochastic processes (demographic stochasticity, stochastic dispersal, and random speciation) but are not driven by selection on trait differ-
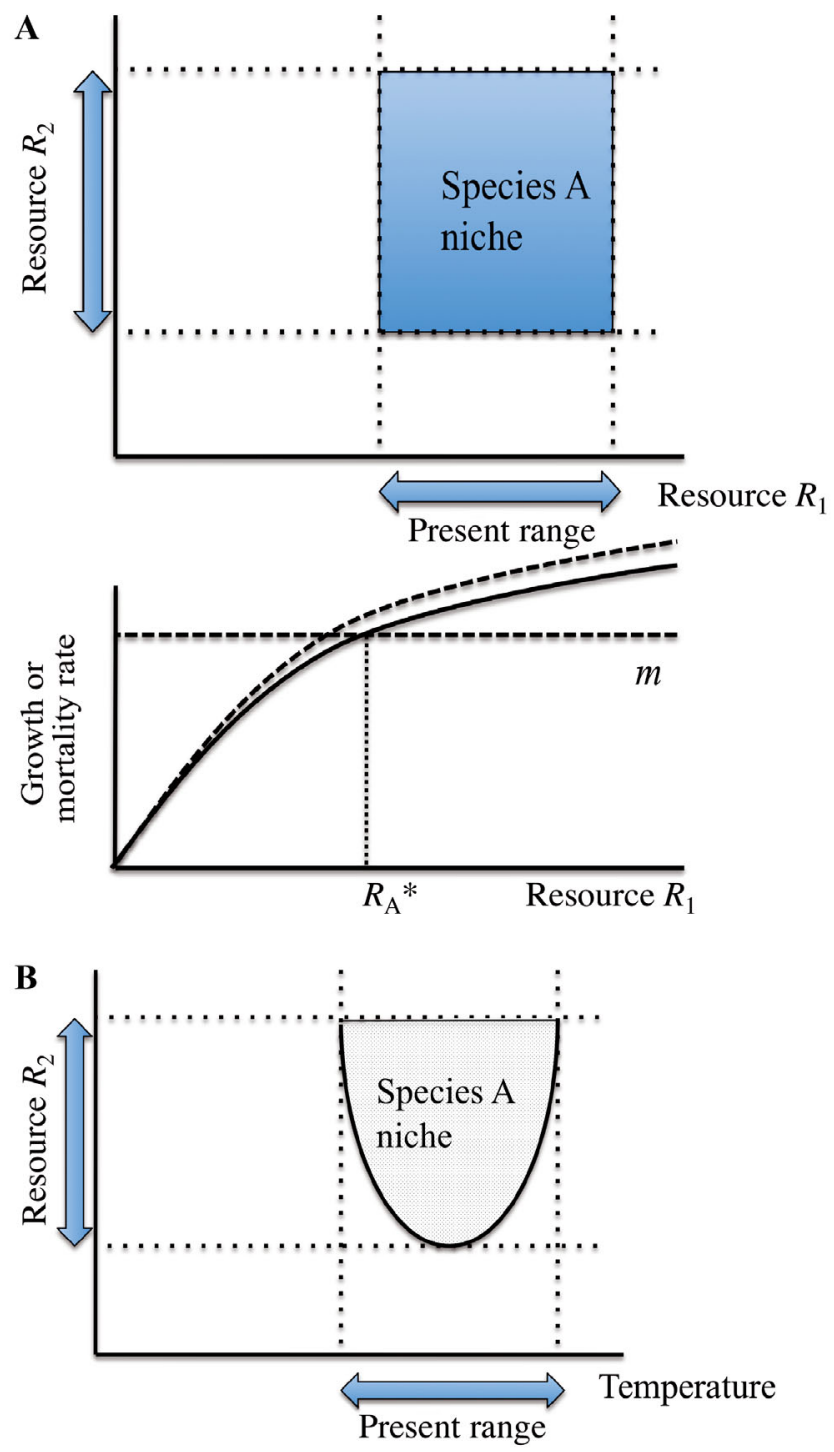

Fig. 2. Mechanistic representation of a niche using functional traits. (A) The growth rate of Species A is described as a function of species traits and resource concentration (Monod function, $\mu=\mu_{\max }\left[R_{1} /\left(R_{1}+k\right)\right]-m$, where $\mu$ is the growth rate, $\mu_{\max }$ is the maximum growth rate, $R_{1}$ is the resource concentration in the environment, $k$ is a half-saturation constant for growth, and $m$ is mortality). A range of that resource occurring in a given environment and leading to positive growth corresponds to the niche range along that resource dimension (upper panel). A similar function can be used for another resource, $R_{2}$ to define the niche range along that resource dimension. The resource concentration at which growth rate equals mortality is called $R^{*}$ and is a measure of species competitive ability for a given resource. For the Monod model, $R^{*}=\left[\mathrm{mk} /\left(\mu_{\max }-m\right)\right] . R_{\mathrm{A}}^{*}$ is the $R^{*}$ of Species A. The dashed line is a growth curve for a different genotype that is a better nutrient competitor (lower $R^{*}$ ). (B) Ecological niche in 2 dimensions, along resource (nutrient) and environmental factor (temperature) axes. Shaded area represents space where species' growth rate is positive, e.g. the niche). The $R^{*}$ (thick lower border of the shaded area) depends on the temperature (Tilman 1982) 
ences (Hubbell 2001). It is clear that most phytoplankton species differ in many aspects of their ecological niches, therefore, not following the assumptions of neutral theory. However, it is intriguing to think that, in some instances, phytoplankton species may appear effectively functionally identical, at least for periods of time. For example, cryptic species documented in phytoplankton (Amato et al. 2007) may not differ noticeably in their traits that affect fitness, thereby behaving neutrally. The differences between the neutral and niche perspectives have been discussed extensively in ecological literature and will not be detailed here.

\section{INTER- AND INTRASPECIFIC TRAIT VARIATION}

A quantitative characterization of species traits and comparisons among species or higher taxa (Edwards et al. 2012) should help predict what species and groups are likely to dominate under changed conditions. For example, species that are good nutrient competitors should increase in their abundance under more severe nutrient limitation that may result from weaker mixing in a warmer ocean (Doney 2006). Functional trait compilations averaged over major functional groups can be used to parameterize phytoplankton community models to predict responses of different groups to various global change stressors (Litchman et al. 2006).

Assessing the range of trait variation under different conditions within a species is needed to characterize the limits to phenotypic plasticity. Most physiological and ecological traits in phytoplankton are inherently plastic, but the ranges differ for different traits. Phytoplankton cell size is highly dependent on the levels of nutrients, light, and temperature (Doucette \& Harrison 1990, Riegman et al. 2000, Montagnes \& Franklin $2001)$. The growth affinity for nitrate $\left(\mu_{\max } / k_{i}\right.$ variables in Fig. 2) was shown to increase with increasing temperature, while the affinity for ammonium had little temperature dependence (Reay et al. 1999). A comprehensive meta-analysis of published physiological experiments measuring species traits under different conditions has not been done, but could provide much needed information on phenotypic plasticity ranges. It is also unknown how species differ in their degree of plasticity for the same traits.

Laboratory experiments measuring physiological traits in phytoplankton are usually carried out on individual strains. In addition to intraspecific trait variation due to different environmental conditions (phenotypic plasticity), different strains grown under identical conditions also exhibit variation in trait values due to genotypic differences (Rynearson \& Armbrust 2004, Kardinaal et al. 2007), providing a basis for selection. Strains better adapted to novel conditions will outcompete less adapted strains, thus changing genotypic frequencies in the population.

\section{NICHE MODELS}

\section{Statistical niche models}

Most current SDMs use observational data on species distributions and relate them statistically to various environmental variables, thereby attempting to define species-realized niches (Kearney et al. 2010). Several major statistical approaches are commonly used; these include generalized linear models (GLMs), generalized additive models (GAMs), genetic (genetic algorithm for rule set production, GARP), and machine-learning algorithms such as Maxent (Wiens et al. 2009).

Due to the prohibitive amount of sampling required to characterize phytoplankton abundance at finer scales, we lack data on the global distributions of most phytoplankton species. However, we can place constraints on their geographic ranges using SDMs. As SDMs are typically correlative, estimating optimal abiotic conditions based on current abundances in the environment, they are not perfect for phytoplankton because of the difficulties estimating species abundances. SDMs have several other shortcomings, among them the inability to clearly separate biotic and anthropogenic influences from underlying abiotic forces and the absence of mechanistic explanations for the observed patterns (Wiens et al. 2009, Kearney et al. 2010).

\section{Mechanistic niche models}

Mechanistic SDMs overcome these issues by using physiological parameters to construct a niche model that is then related to current environmental conditions to derive a maximal species range (Kearney \& Porter 2009). The species' range by this model is therefore the geographic limit of its fundamental niche. This approach has not been widely applied to marine taxa, despite being well suited to them by virtue of having stable, highly predictable, and wellconnected environments (Robinson et al. 2011).

Phytoplankton meet many of the assumptions of this method, including being strongly influenced by abi- 
otic factors, being less dispersal-limited than most taxa due to ocean circulation, and lacking in behaviors that can modify environmental influences. In addition, the physiological traits needed to parameterize niche models, such as the effects of changes in nutrient concentration, light, temperature, and salinity on fitness have been measured in a number of phytoplankton species (Litchman \& Klausmeier 2008, Schwaderer et al. 2011, Edwards et al. 2012). The reactions norms that phytoplankton exhibit in response to these environmental drivers are strongly non-linear, which is difficult to capture in correlative SDMs. For example, species responses to temperature are highly skewed, with lethal temperatures often a few degrees above the optimum temperature for growth (Kingsolver 2009).

An example of using mechanistic SDMs is shown in Fig. 3. The geographic range of the tropical cyano-

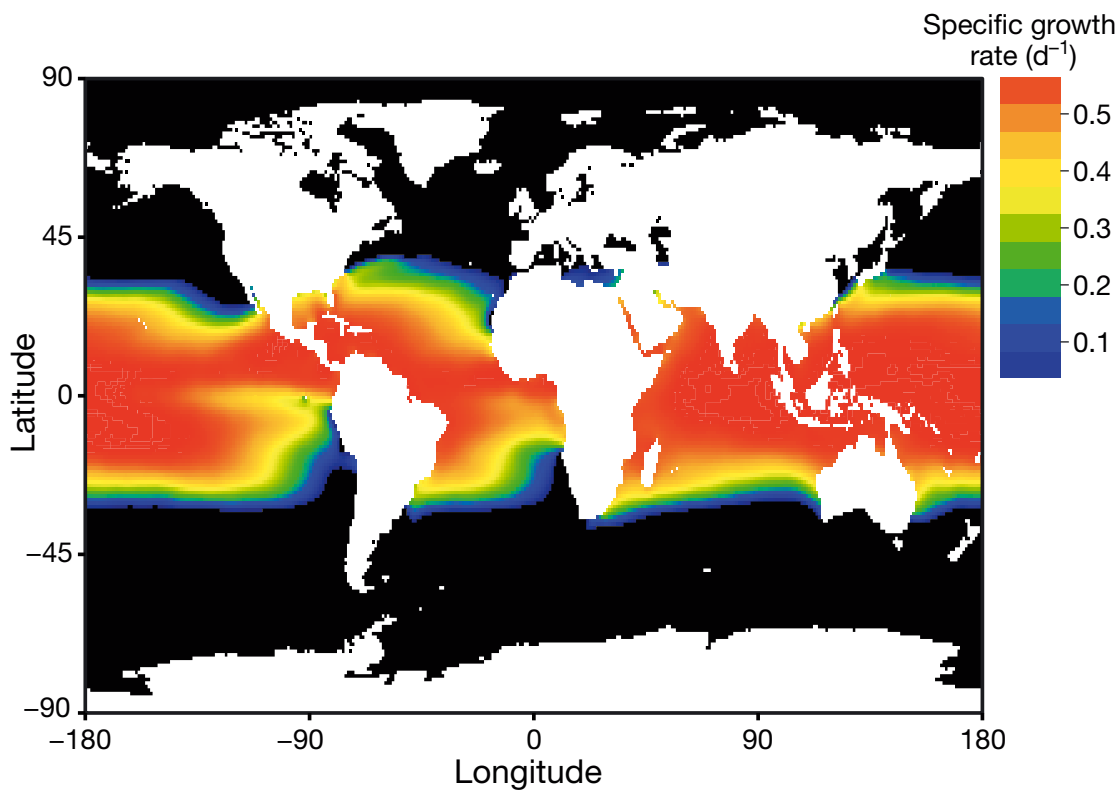

Fig. 3. Predicted species range of cyanobacterium Trichodesmium erythraeum Strain GBRTRLI101 based on its thermal tolerance curve (Chappell \& Webb 2010) Colour variation indicates predicted variation in positive growth rates (which could imply variation in abundance), while growth rates at or below zero are shown as black. This species is generally found in tropical and subtropical waters (Karl et al. 2002)

bacterium Trichodesmium erythraeum was estimated using its thermal tolerance curve (Chappell \& Webb 2010), fitted to the function of Norberg (2004), and the monthly mean ocean temperature data from the NOAA World Ocean Atlas 2009 (Locarnini et al. 2010). Growth rates were calculated based on monthly temperatures to account for seasonal temperature changes, and the range depicted with color variation covers areas where the mean annual growth rate is estimated to be positive. Though our ability to validate these model predictions is currently limited, they do agree with our understanding of Trichodesmium erythraeum as a tropical and subtropical species (Karl et al. 2002). The predicted range corresponds to the fundamental thermal niche of this species, and it is likely that temperature also controls its abundance and growth indirectly, by regulating stratification and nutrient supply (Monteiro et al. 2011). Disentangling the effects of different environmental factors on species niches is complicated, and caution should be exercised when interpreting the resulting species ranges. We may extend this approach by incorporating multiple environmental parameters simultaneously, but we are currently limited by our understanding of how major environmental drivers interact to affect population growth rates. Characterizing the nature of the interactions between temperature, nutrients, and light in a group of species would provide a useful base to extend this into multiple trait and environmental dimensions. Additionally, this approach would greatly benefit from the incorporation of intraspecific variation in traits, as local adaptation would tend to bias estimates based on single cultures. Other factors, such as competition, grazing, and dispersal will limit this range further, though source-sink dynamics may extend the boundaries as well.

Range predictions may similarly be made based on environmental predictions from global climate models. A comparison of existing and future ranges would enable us to better predict changes in elemental cycling in different parts of the ocean, such as potential poleward shifts in populations of nitrogenfixing cyanobacteria.

\section{USING TRAITS TO REVEAL MECHANISMS BEHIND COMMUNITY STRUCTURE}

A fundamental challenge in basic and applied ecology is the prediction of community composition from environmental conditions. A common approach to this problem is to use time series data or spatially extensive surveys to analyze how different taxonomic groups respond to environmental variation. A limitation of this approach is that the resulting patterns can be difficult to interpret in terms of underly- 
ing mechanisms. For example, in the western English Channel there is a somewhat regular procession of diatom species/genera as the environment shifts from presumed light limitation during the winter, through spring bloom conditions, to presumed nutrient limitation during the summer (Widdicombe et al. 2010). What mechanism(s) cause this seasonal shift in diatom composition? Because multiple environmental variables change in a partially correlated way (light, temperature, nitrate, phosphate, silicate, grazer abundance, and composition), and because different species or genera vary in multiple ways, it is difficult to dissect the causes of seasonal variation in composition. However, in order to predict how communities will respond to environmental change, including potentially new combinations of environmental conditions, it will be necessary to have a strong mechanistic foundation for understanding community composition and dynamics.

A focus on functional traits has the potential to provide a more mechanistic basis for understanding the causes of shifts in community composition. Much work in this vein has already been performed in terrestrial plant communities. For example, Cornwell \& Ackerly (2009) measured plant community composition across the varied topography of coastal California, and at the same time measured 14 leaf and stem traits on 54 species that occurred in these communities. These data allowed them to test whether community-averaged trait values changed along environmental gradients. Among other patterns, they found that community-average specific leaf area (leaf area divided by leaf dry mass) increased with increasing soil water content. This pattern is consistent with a trade-off, whereby higher specific leaf area increases potential productivity at the expense of resource use efficiency. Therefore, their results suggest that changing soil water content alters community composition by selecting for species with the locally optimal specific leaf area.

There are distinct advantages and disadvantages of applying such a trait-based approach to community variation in marine phytoplankton. A primary advantage is the strong link between commonly measured phytoplankton traits and the processes of resource acquisition and usage (Litchman \& Klausmeier 2008). For example, much of the ecophysiology of nutrient acquisition and nutrient-limited growth can be captured by measuring the Michaelis-Menten uptake curve and the Droop curve for growth rate as a function of nutrient quota (Grover 1991). Compared to common terrestrial plant traits such as wood density and seed mass (e.g. Cornwell \& Ackerly 2009), the parameters of these curves are more clearly linked to ecophysiology and population dynamics. The disadvantage of applying these traits to community analyses is that they are relatively labor intensive to measure and hence have been measured for relatively few species. Therefore, quantifying the community average of a trait, such as the minimum subsistence quota for nitrogen, will be a significant undertaking.

Although quantifying trait values for an entire community is ideal, it is possible to use a subset of species to test for the role of functional traits in determining community response to multiple environmental factors. For example, we may predict that, in the western English Channel, better nitrogen competitors should have a relative advantage during summer periods, when nitrate is often reduced below the detection limit (Smyth et al. 2010). Using laboratorymeasured parameters of Michaelis-Menten uptake and Droop growth curves, we can make a priori predictions of the relative competitive ability of nitrate for those species for which we have such data (Edwards et al. 2011). We can then test whether species-specific responses to nitrate concentration are consistent with interspecific trait differences. In particular, we can predict that good nitrogen competitors will experience a relative advantage as nitrate becomes rare. In a regression framework, this will be

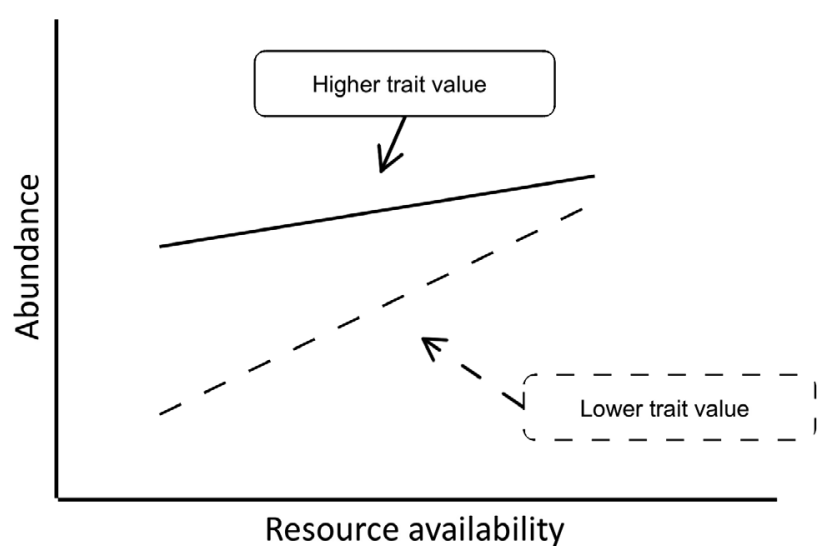

Fig. 4. Example of how functional trait differences will result in predictable differences between species in response to environmental variation. Assume a trait is measured that approximates competitive ability for a resource. Across a gradient of resource availability, species' abundances should change in such a way that better competitors (higher trait) increase in relative abundance as the resource decreases and becomes more limiting. In a linear statistical model, the effect of the trait can be quantified as an interaction between the trait value and the slope of abundance versus resource availability. The particular slopes and intercepts shown here are merely one example, as the prediction concerns the relative values of the slopes, i.e. higher trait 
evident as a difference in slopes of abundance versus nitrate concentration, which can be tested as an interaction between a species' trait and its slope versus nitrate (Webb et al. 2010, Schwaderer et al. 2011; Fig. 4).

Preliminary analyses indicate that this approach can detect strong effects of functional traits on interspecific differences in response to environmental change (Edwards et al. in press). By using multiple regression, this approach can be applied to multiple trait-environment interactions simultaneously, which allows one to test for particular trait-environment linkages while controlling for the effects of other environmental factors that vary simultaneously. In summary, we can establish a mechanistic foundation for the relation between environmental change and community composition, by formulating a priori predictions of trait-environment interactions and testing those with appropriate statistical models.

This approach also integrates naturally with a mechanistic approach to the niche and the geographic distribution of species. The same traits that are used in a mechanistic niche model can be used to make predictions about the relative performance of species under particular environmental conditions. For example, in a nitrogen-limited region of the ocean, a mechanistic niche model will predict that some set of species can each individually persist under those particular nitrogen supply conditions; in Hutchinsonian terms, this region is therefore part of the fundamental niche of these species. However, within this set of species, some species will be relatively better nitrogen competitors and will therefore be expected to attain higher abundance, and perhaps exclude other species entirely. In this way, it is possible to translate from models of the fundamental niche to the observed realized niche, using traitbased predictions. Furthermore, by using functional trait information to parameterize population dynamic models (see section 'Models of trait evolution and community assembly'), it is possible to make explicit predictions about what species or trait values can coexist under particular environmental conditions.

\section{TRADE-OFFS AND RESPONSES TO MULTIPLE STRESSORS}

The majority of species traits are not independent but positively or negatively correlated; these correlations often represent trade-offs and result in contrasting ecological strategies (Margalef 1978, Litchman et al. 2007, Schwaderer et al. 2011). Trade-offs are es- sential for explaining species coexistence and diversity (Tilman 1990) and niche differences (Chase \& Leibold 2003).

Trade-offs are especially important when multiple stressors act simultaneously. Because of the tradeoffs, a species that performs well under one environmental stressor, such as an elevated temperature, may not fare well when another stressor, such as increased $\mathrm{CO}_{2}$, is acting simultaneously. The tradeoffs reflect energy and material constraints on the investment into major functions: for example, investing into cellular machinery for growth (ribosomes) may limit investment into light-harvesting machinery (chloroplasts) (Klausmeier et al. 2004). If higher $\mathrm{CO}_{2}$ increases sensitivity to photoinhibition (Wu et al. 2010), a simultaneous production of heat shock proteins in response to rising temperatures may limit the investment into photoprotective compounds. However, heat shock proteins may also be useful in photoprotection (Schroda et al. 1999). Determining the nature of trade-offs in phytoplankton is, therefore, crucial for predicting species and community responses to diverse global change factors. This is an active area of research and many trade-offs have been documented for phytoplankton, including a 3way trade-off between nitrogen and phosphorus competitive abilities and cell size (proxy for grazer resistance) (Litchman et al. 2007, Edwards et al. 2011, Schwaderer et al. 2011). However, many more trade-offs remain to be discovered and their mechanistic basis understood. It is also important to determine how rigid the observed trade-offs are and whether species can deviate from them.

\section{MULTIVARIATE TRAIT STRUCTURE}

We may expect that different environmental factors have distinct effects on community composition and ecosystem processes. However, whether this is true will depend on patterns of interspecific covariation of multiple performance functions. For example, nitrogen pollution could shift production in coastal ecosystems from nitrogen limitation to phosphorus limitation. Furthermore, if there is a strong trade-off across species in competitive ability for $\mathrm{N}$ versus $\mathrm{P}$, we would expect a large shift in composition, from better N competitors to better P competitors. However, the regional species pool may not exhibit such trait variation, and instead, multiple performance criteria may be positively correlated. For example, if smaller cells tend to be better competitors for all nutrients (Edwards et al. 2011), but species of similar 
size do not vary in $\mathrm{N}$ versus $\mathrm{P}$ ability, then a shift from $\mathrm{N}$ to $\mathrm{P}$ limitation may not lead to a strong shift in composition. Therefore, it is important to distinguish between the existence of functional trade-offs and the degree to which interspecific variation is organized along those trade-off axes: past selection may not have led to significant phenotypic variation along all possible trait axes.

Some evidence for the importance of this perspective comes from an analysis of the covariation among the competitive ability for nitrogen, the competitive ability for phosphorus, and cell size in freshwater and marine phytoplankton (Edwards et al. 2011). When combining freshwater and marine species, there is evidence for a general 3-way trade-off among the competition for $\mathrm{N}$, the competition for $\mathrm{P}$, and cell size. However, the dominant axes of trait variation differ between freshwater and marine systems: freshwater algae vary primarily along an $\mathrm{N}$ versus $\mathrm{P}$ competition axis, while marine species vary primarily along a size axis, where increased size is correlated with decreased competitive ability for both nutrients. Based on these results, it is plausible that a large change in the $\mathrm{N}: \mathrm{P}$ supply ratio would result in a large change in the composition in freshwater systems, but a smaller change in the composition in marine systems. More generally, the response of a community to environmental change will depend on the structure of trait covariation created by past environments and evolution. By quantifying the multivariate patterns of interspecific trait variation, it is possible to test for trade-offs and to quantify what performance functions tend to covary positively and which vary independently. Using these patterns, it is then possible to project what kinds of communities can possibly occur in response to rapid environmental change. If climate change leads to novel combinations of environmental conditions, the resulting community may be poorly adapted to those conditions until evolution is able to explore new regions of trait space.

\section{TRAIT AND NICHE EVOLUTION}

Changing environmental conditions, including anthropogenic global change, may alter not only the levels of resources and environmental factors, thereby affecting species-realized niches, but may also lead to evolutionary changes in trait values. Traits characterizing resource utilization or responses to environmental factors (e.g. thermal niche) may evolve, leading to a better adaptation to novel selection regimes. Changes in trait values will thereby alter a species' fundamental niche. Niche evolution may be widespread in phytoplankton because large population numbers, fast generation times, high genotypic diversity, and various selective pressures likely lead to trait evolution. Understanding trait evolution is, therefore, necessary for characterizing niche dynamics at present and in the future. In the following section we outline ways to address the potential for trait evolution, both experimentally and theoretically.

\section{EVOLUTION EXPERIMENTS}

\section{Experiments with individual species}

Experimental investigation of how key traits may evolve in response to global change is a promising and much needed approach for marine phytoplankton and other planktonic organisms. There is a rich field of experimental evolution that uses bacteria, insects, terrestrial plants, and other organisms (Elena \& Lenski 2003, Garland \& Rose 2009, De Meester et al. 2011), but experimental studies on phytoplankton evolution are just beginning. The most relevant studies to what we propose here are the pioneering experiments on the evolutionary responses of the freshwater algae Chlamydomonas to a global change stressor, increased $\mathrm{CO}_{2}$, carried out by G. Bell and S. Collins (Collins \& Bell 2004, 2006). Evolution experiments are often done with single clones, and evolutionary changes arise as a result of mutations or genetic recombination (Garland \& Rose 2009). However, in nature, most populations, including marine phytoplankton species, are comprised of many different genotypes and, as a result, exhibit intraspecific variation in trait values (Rynearson \& Armbrust 2000, Rynearson et al. 2006). This intraspecific trait variation provides a rich basis for selection of the best adapted genotypes, often leading to a faster evolutionary response compared to monoclonal responses (Yoshida et al. 2003, Barrett \& Schluter 2008). However, it is also possible that in large populations of asexual organisms, clonal interference, where clones with beneficial mutations compete with each other, may slow down adaptation (Kao \& Sherlock 2008). We suggest that evolution experiments with marine (and freshwater) phytoplankton and other organisms should be carried out both with single clones, to address the role of mutation in evolutionary response, and with multiple clones, to better reflect selection scenarios in nature. A just published study on the bloom-forming coccolithophorid Emiliania huxleyi experimentally 
evolved both individual clones and clone mixtures under increased $\mathrm{CO}_{2}$ concentrations (Lohbeck et al. 2012). Experiments with monocultures combined with genetic analyses allowed determination of what genes are involved in a particular phenotypic/trait change, as, even for the same selection regimes, there may be distinct adaptation paths involving different genes and resulting in different states of fitness (Elena \& Lenski 2003). Using ecologically and biogeochemically important species and species whose genomes were or are being sequenced and annotated would maximize the efficiency and usefulness of the experimental evolution studies.

The initial assessment of the genetic and phenotypic (trait variation) diversity will allow us to make predictions on the adaptation potential, both in experimental and natural populations. If the trait variation present in different genotypes is high, the population is more likely to respond adaptively to changing conditions and the rate of such response may be faster (Barrett \& Schluter 2008). In marine phytoplankton, standing genetic variation and, possibly, trait variation may be high not only due to frequent mutations and changing selection pressures, but also due to gene flow from populations experiencing different environmental conditions via longdistance transport by currents and other types of water movement (Rynearson \& Armbrust 2005).

To determine the pattern and rates of trait evolution, the trait distribution is assessed at the beginning of and throughout the experiment; the trait's mean values and variance are usually of interest. Adaptation can lead to changes either in means or variance or both, and will arise due to mutations, recombination, or clonal selection.

Most evolution experiments consider a single selective factor, and, to the best of our knowledge, investigations of the effects of multiple environmental stressors simultaneously on trait evolution have not been carried out. This is clearly a research direction that needs to be pursued urgently in the face of multidimensional global environmental change. For example, determining how rising temperatures and $\mathrm{CO}_{2}$ concentration would affect evolution of phytoplankton functional traits would be very informative, as it is unknown if the selection pressures from the 2 stressors have an opposing or a synergistic effect (or no interaction) on traits and the niche.

A possible approach would be to conduct complete or incomplete factorial experiments with factors being major global change stressors, such as temperature, high $\mathrm{CO}_{2}$, or high or low nutrient concentrations. Such experiments can be carried out both with single strains and strain mixtures to reflect the genetic diversity occurring in nature.

\section{Community experiments}

Although evolution experiments with individual species may show the potential of different species to adapt to various stressors, even acting simultaneously, the evolutionary responses in natural conditions will most likely also depend on the community composition in which the focal species is embedded (Van Doorslaer et al. 2010). Experiments with Daphnia showed that its microevolutionary responses to high temperature had the opposite pattern in a community compared to that a in monoculture (Van Doorslaer et al. 2010). Collins (2011) found that the evolutionary response of Chlamydomonas to increased $\mathrm{CO}_{2}$ depended on whether the strains were grown in isolation or in mixtures.

It has been shown theoretically that, in communities, evolutionary responses of individual species to changing conditions may be hindered by the presence of other species that are already better adapted to the new conditions (de Mazancourt et al. 2008). With increasing diversity, the probability that such well-adapted species are present increases, and consequently, the evolutionary response may not be as strong in diverse communities as in monocultures or low-diversity communities (de Mazancourt et al. 2008). As a result, instead of evolutionary changes, species sorting (replacement) may be the dominant community (or metacommunity) response to novel environmental conditions.

These and other theoretical findings make it necessary to investigate evolution of species traits in the context of other species. The presence of predators or parasites may also alter the trajectory and the end result of adaptation. Therefore, we propose that evolution experiments investigating the effects of competitors, predators, and parasites on species evolutionary responses are a much-needed direction for experimental evolution studies. Of course, community composition changes frequently, and it would be impossible to run evolution experiments with all the species combinations that a species in question encounters. However, as a first step, it would be informative to contrast species trait evolution in the absence and presence of a competitor and/or predator. A more thorough investigation of trait evolution in the community context could be done using modeling approaches that we briefly outline in the following section. 


\section{MODELS OF TRAIT EVOLUTION AND COMMUNITY ASSEMBLY}

A range of theoretical frameworks exists for the trait-based modeling of marine communities. These include (1) extensions of traditional community ecology, where a large number of species are allowed to sort out (randomly chosen species, Follows et al. 2007; a near-continuous range of species, Bruggeman \& Kooijman 2007); (2) moment methods that approximate the community by total biomass, mean trait, and trait variance (Wirtz \& Eckhardt 1996, Norberg et al. 2001, Savage et al. 2007, Merico et al. 2009); (3) multispecies models that combine population and trait dynamics as in quantitative genetics (Abrams \& Matsuda 1997, Norberg et al. 2012); (4) mutation-limited evolution in adaptive dynamics (Geritz et al. 1997), and (5) evolutionary game theory, which focuses on uninvadable sets of species (Brown \& Vincent 1992, Klausmeier et al. 2007, Litchman et al. 2009). What these approaches have in common is that they explicitly define species by their ecologically relevant traits. Moreover, they often make the same prediction about the endpoint of community assembly/ evolution (Abrams 2001). They differ primarily in their assumptions about the sources of phenotypic diversity (rare mutation, genetic variation maintained by mutation-selection balance, immigration, 'everything is everywhere').

Few of these approaches have been used to predict how species and communities will respond to global change, but it is likely that they will differ in their predictions, because adaptation to a changing environment relies on phenotypic diversity. For example, in 3 disparate modeling frameworks (quantitative genetics [QG], adaptive dynamics [AD], and moment methods [MM]), the response of a trait to selection is proportional to the product of the trait variance and the selection gradient (QG: Lande 1979; AD: Dieckmann \& Law 1996; MM: Norberg et al. 2001, Savage et al. 2007), but the source of variance differs (common or rare mutation or immigration). Therefore, accurately parameterizing the mechanisms that maintain or bring new phenotypes into the community is a key challenge in using trait-based models to predict response to global change.

A related issue particularly relevant in the response to multiple stressors is the covariance among multiple traits. This sets the ability for short-term adaptation (Lande 1979, Arnold 1992, Savage et al. 2007). When there are negative correlations between traits that are both being selected for, adaptation is hampered. This trait covariance is set by both the past selective regimes, as well as the input of new phenotypes due to mutation, which is subject to functional constraints (Arnold 1992), or immigration, which is determined by the traits of species in the regional species pool (Savage et al. 2007). Elucidating these functional constraints and determinants of metacommunity diversity (Norberg et al. 2012) is another important task.

\section{CONCLUSIONS}

Species and communities will undoubtedly respond to multifaceted global environmental change. Several mechanisms with overlapping time scales, such as phenotypic plasticity, species sorting, and genetic adaptation, will likely be involved. It is, however, unknown what the rate and the relative importance of the potential response mechanisms would be. Given the pressing need to assess how species and communities will respond to multiple stressors, ecologists and evolutionary biologists can approach the problem from multiple angles, using diverse experimental and modeling approaches. We propose several research directions to help advance the field and increase its predictive power. First, we can collect experimental data on major functional traits (and their plasticity) and combine it with the data on species distributions along major environmental gradients to map ecological niches. A combination of statistical and mechanistic niche descriptions may result in the most precise niche characterizations. Second, we can conduct evolution experiments, both with single strains and diverse populations to determine the adaptation potential and the exact mechanisms of adaptation. A simultaneous consideration of several key environmental stressors, such as temperature and $\mathrm{CO}_{2}$, is necessary to increase the realism and to understand multiple stressor interactions. Third, the development of novel models of (phyto)plankton community organization and evolution should allow a detailed exploration of various global change scenarios and the role of community and food web composition in adaptation to global change.

Acknowledgements. E.L. thanks P. Boyd and D. Hutchins for inviting her to give a talk at the ASLO Ocean Sciences meeting 2010 that led to the development of the present paper. This research was in part supported by the NSF grants DEB0845932, DEB-0845825, OCE-0928819 and DEB-1136710 (to E.L. and C.A.K.), the J. S. McDonnell Foundation grant (to C.A.K. and E.L.), the NSF BEACON grant (to E.L., C.A.K., and V. Armbrust), and the Marie Curie International Fellowship to C.A.K. This is Kellogg Biological Station Contribution 1701. 


\section{LITERATURE CITED}

Abrams PA (2001) Modelling the adaptive dynamics of traits involved in inter- and intraspecific interactions: an assessment of three methods. Ecol Lett 4:166-175

Abrams PA, Matsuda H (1997) Fitness minimization and dynamic instability as a consequence of predator-prey coevolution. Evol Ecol 11:1-20

> Ackerly DD (2003) Community assembly, niche conservatism, and adaptive evolution in changing environments. Int J Plant Sci 164:S165-S184

Amato A, Kooistra W, Ghiron JHL, Mann DG, Proschold T, Montresor M (2007) Reproductive isolation among sympatric cryptic species in marine diatoms. Protist 158: 193-207

Arnold SJ (1992) Constraints on phenotypic evolution. Am Nat 140:S85-S107

> Barrett RDH, Schluter D (2008) Adaptation from standing genetic variation. Trends Ecol Evol 23:38-44

$>$ Brown JS, Vincent TL (1992) Organization of predator-prey communities as an evolutionary game. Evolution 46: 1269-1283

> Brown CW, Yoder JA (1994) Coccolithophorid blooms in the global ocean. J Geophys Res 99:7467-7482

> Bruggeman J, Kooijman S (2007) A biodiversity-inspired approach to aquatic ecosystem modeling. Limnol Oceanogr 52:1533-1544

> Chappell PD, Webb EA (2010) A molecular assessment of the iron stress response in the two phylogenetic clades of Trichodesmium. Environ Microbiol 12:13-27

> Charmantier A, McCleery RH, Cole LR, Perrins C, Kruuk LEB, Sheldon BC (2008) Adaptive phenotypic plasticity in response to climate change in a wild bird population. Science 320:800-803

Chase JM, Leibold MA (2003) Ecological niches: linking classical and contemporary approaches. Chicago University Press, Chicago, IL

> Collins S (2011) Competition limits adaptation and productivity in a photosynthetic alga at elevated $\mathrm{CO}_{2}$. Proc Biol Sci 278:247-255

> Collins S, Bell G (2004) Phenotypic consequences of 1,000 generations of selection at elevated $\mathrm{CO}_{2}$ in a green alga. Nature 431:566-569

Collins S, Bell G (2006) Evolution of natural algal populations at elevated $\mathrm{CO}_{2}$. Ecol Lett 9:129-135

> Colwell RK, Rangel TF (2009) Hutchinson's duality: the once and future niche. Proc Natl Acad Sci USA 106: 19651-19658

Cornwell WK, Ackerly DD (2009) Community assembly and shifts in plant trait distributions across an environmental gradient in coastal California. Ecol Monogr 79:109-126

de Mazancourt C, Johnson E, Barraclough TG (2008) Biodiversity inhibits species' evolutionary responses to changing environments. Ecol Lett 11:380-388

> De Meester L, Van Doorslaer W, Geerts A, Orsini L, Stoks R (2011) Thermal genetic adaptation in the water flea Daphnia and its impact: an evolving metacommunity approach. Integr Comp Biol 51:703-718

> Dieckmann U, Law R (1996) The dynamical theory of coevolution: a derivation from stochastic ecological processes. J Math Biol 34:579-612

> Doney SC (2006) Oceanography: plankton in a warmer world. Nature 444:695-696

$>$ Doucette GJ, Harrison PJ (1990) Some effects of iron and nitrogen stress on the red tide dinoflagellate Gymno- dinium sanguineum. Mar Ecol Prog Ser 62:293-306

$>$ Edwards KF, Klausmeier CA, Litchman E (2011) Evidence for a three-way tradeoff between nitrogen and phosphorus competitive abilities and cell size in phytoplankton. Ecology 92:2085-2095

Edwards KF, Thomas MK, Klausmeier CA, Litchman E (2012) Allometric scaling and taxonomic variation in nutrient utilization traits and growth rates of marine and freshwater phytoplankton. Limnol Oceanogr 57:554-566

Edwards KF, Litchman E, Klausmeier CA (in press) Functional traits explain phytoplankton community structure and seasonal dynamics in a marine ecosystem. Ecol Lett

> Elena SF, Lenski RE (2003) Evolution experiments with microorganisms: the dynamics and genetic bases of adaptation. Nat Rev Genet 4:457-469

Falkowski PG, Fenchel T, Delong EF (2008) The microbial engines that drive Earth's biogeochemical cycles. Science 320:1034-1039

Field CB, Behrenfeld MJ, Randerson JT, Falkowski PG (1998) Primary production of the biosphere: integrating terrestrial and oceanic components. Science 281: $237-240$

> Follows MJ, Dutkiewicz S, Grant S, Chisholm SW (2007) Emergent biogeography of microbial communities in a model ocean. Science 315:1843-1846

Garland T, Rose MR (eds) (2009) Experimental evolution: concepts, methods, and applications of selection experiments. University of California Press, Berkeley, CA

Geritz SAH, Kisdi E, Meszena G, Metz JAJ (1997) Evolutionary singular strategies and the adaptive growth and branching of the evolutionary tree. Evol Ecol 12:35-57

> Grover JP (1991) Resource competition in a variable environment: phytoplankton growing according to the variable-internal-stores model. Am Nat 138:811-835

Guisan A, Thuiller W (2005) Predicting species distribution: offering more than simple habitat models. Ecol Lett 8: 993-1009

Hubbell SP (2001) The unified neutral theory of biodiversity and biogeography. Princeton University Press, Princeton, NJ

Hutchinson GE (1957) Concluding remarks. Cold Spring Harb Symp Quant Biol 22:415-427

> Kao KC, Sherlock G (2008) Molecular characterization of clonal interference during adaptive evolution in asexual populations of Saccharomyces cerevisiae. Nat Genet 40: 1499-1504

Kardinaal WEA, Tonk L, Janse I, Hol S, Slot P, Huisman J, Visser PM (2007) Competition for light between toxic and nontoxic strains of the harmful cyanobacterium Microcystis. Appl Environ Microbiol 73:2939-2946

Karl D, Michaels A, Bergman B, Capone D and others (2002) Dinitrogen fixation in the world's oceans. Biogeochemistry 57:47-98

Kearney M, Porter W (2009) Mechanistic niche modelling: combining physiological and spatial data to predict species' ranges. Ecol Lett 12:334-350

Kearney M, Simpson SJ, Raubenheimer D, Helmuth B (2010) Modelling the ecological niche from functional traits. Philos Trans R Soc Lond B Biol Sci 365:3469-3483

> Kingsolver JG (2009) The well-temperatured biologist. Am Nat 174:755-768

Klausmeier CA, Litchman E, Daufresne T, Levin SA (2004) Optimal nitrogen-to-phosphorus stoichiometry of phytoplankton. Nature 429:171-174

Klausmeier CA, Litchman E, Levin SA (2007) A model of 
flexible uptake of two essential resources. J Theor Biol 246:278-289

Lande R (1979) Quantitative genetic analysis of multivariate evolution, applied to brain-body size allometry. Evolution 33:402-416

Leibold MA (1995) The niche concept revisited: mechanistic model and community context. Ecology 76:1371-1382

$>$ Li WKW, McLaughlin FA, Lovejoy C, Carmack EC (2009) Smallest algae thrive as the Arctic Ocean freshens. Science 326:539

Litchman E, Klausmeier CA (2008) Trait-based community ecology of phytoplankton. Annu Rev Ecol Evol Syst 39: 615-639

Litchman E, Klausmeier CA, Miller JR, Schofield OM, Falkowski PG (2006) Multi-nutrient, multi-group model of present and future oceanic phytoplankton communities. Biogeosciences 3:585-606

> Litchman E, Klausmeier CA, Schofield OM, Falkowski PG (2007) The role of functional traits and trade-offs in structuring phytoplankton communities: scaling from cellular to ecosystem level. Ecol Lett 10:1170-1181

> Litchman E, Klausmeier CA, Yoshiyama K (2009) Contrasting size evolution in marine and freshwater diatoms. Proc Natl Acad Sci USA 106:2665-2670

> Litchman E, de Tezanos Pinto P, Klausmeier CA, Thomas MK, Yoshiyama K (2010) Linking traits to species diversity and community structure in phytoplankton. Hydrobiologia 653:15-38

Locarnini RA, Mishonov AV, Antonov JI, Boyer TP and others (2010) World ocean atlas 2009, Vol. 1. Temperature. In: Levitus S (ed) NOAA atlas NESDIS 68. NOAA, Washington, DC

Lohbeck KT, Riebesell U, Reusch TBH (2012) Adaptive evolution of a key phytoplankton species to ocean acidification. Nat Geosci 5:346-351

Margalef R (1978) Life forms of phytoplankton as survival alternatives in an unstable environment. Oceanol Acta 1: 493-509

McGill BJ, Enquist BJ, Weiher E, Westoby M (2006) Rebuilding community ecology from functional traits. Trends Ecol Evol 21:178-185

Merico A, Bruggeman J, Wirtz K (2009) A trait-based approach for downscaling complexity in plankton ecosystem models. Ecol Model 220:3001-3010

- Montagnes DJS, Franklin DJ (2001) Effect of temperature on diatom volume, growth rate, and carbon and nitrogen content: reconsidering some paradigms. Limnol Oceanogr 46:2008-2018

Monteiro FM, Dutkiewicz S, Follows MJ (2011) Biogeographical controls on the marine nitrogen fixers. Global Biogeochem Cycles 25:GB2003

Nicotra AB, Atkin OK, Bonser SP, Davidson AM and others (2010) Plant phenotypic plasticity in a changing climate. Trends Plant Sci 15:684-692

Norberg J (2004) Biodiversity and ecosystem functioning: a complex adaptive systems approach. Limnol Oceanogr 49:1269-1277

Norberg J, Swaney DP, Dushoff J, Lin J, Casagrandi R, Levin SA (2001) Phenotypic diversity and ecosystem functioning in changing environments: a theoretical framework. Proc Natl Acad Sci USA 98:11376-11381

Norberg J, Urban MC, Vellend M, Klausmeier CA, Loeuille N (2012) Eco-evolutionary responses of biodiversity to climate change. Nat Clim Change 2:747-751

- Pearman PB, Guisan A, Broennimann O, Randin CF (2008)
Niche dynamics in space and time. Trends Ecol Evol 23: 149-158

Peterson AT, Soberón J, Sánchez-Cordero V (1999) Conservatism of ecological niches in evolutionary time. Science 285:1265-1267

Polechova J, Storch D (2008) Ecological niche. In: Jørgensen $\mathrm{SE}$, Fath BD (eds) Encyclopedia of ecology. Elsevier, Oxford, p 1088-1097

> Reay DS, Nedwell DB, Priddle J, Ellis-Evans JC (1999) Temperature dependence of inorganic nitrogen uptake: reduced affinity for nitrate at suboptimal temperatures in both algae and bacteria. Appl Environ Microbiol 65: 2577-2584

Riegman R, Stolte W, Noordeloos AAM, Slezak D (2000) Nutrient uptake and alkaline phosphatase (EC 3:1:3:1) activity of Emiliania huxleyi (Prymnesiophyceae) during growth under $\mathrm{N}$ and $\mathrm{P}$ limitation in continuous cultures. J Phycol 36:87-96

Robinson LM, Elith J, Hobday AJ, Pearson RG, Kendall BE, Possingham HP, Richardson AJ (2011) Pushing the limits in marine species distribution modelling: lessons from the land present challenges and opportunities. Glob Ecol Biogeogr 20:789-802

Rynearson TA, Armbrust EV (2000) DNA fingerprinting reveals extensive genetic diversity in a field population of the centric diatom Ditylum brightwellii. Limnol Oceanogr 45:1329-1340

> Rynearson TA, Armbrust EV (2004) Genetic differentiation among populations of the planktonic marine diatom Ditylum brightwellii (Bacillariophyceae). J Phycol 40: 34-43

> Rynearson TA, Armbrust EV (2005) Maintenance of clonal diversity during a spring bloom of the centric diatom Ditylum brightwellii. Mol Ecol 14:1631-1640

> Rynearson TA, Newton JA, Armbrust EV (2006) Spring bloom development, genetic variation, and population succession in the planktonic diatom Ditylum brightwellii. Limnol Oceanogr 51:1249-1261

Savage VM, Webb CT, Norberg J (2007) A general multitrait-based framework for studying the effects of biodiversity on ecosystem functioning. J Theor Biol 247: 213-229

> Schroda M, Vallon O, Wollman FA, Beck CF (1999) A chloroplast-targeted heat shock protein 70 (HSP70) contributes to the photoprotection and repair of photosystem II during and after photoinhibition. Plant Cell 11: 1165-1178

> Schwaderer AS, Yoshiyama K, Pinto Pd T, Swenson NG, Klausmeier CA, Litchman E (2011) Eco-evolutionary patterns in light utilization traits and distributions of freshwater phytoplankton. Limnol Oceanogr 56:589-598

Smyth TJ, Fishwick JR, Al-Moosawi L, Cummings DG and others (2010) A broad spatio-temporal view of the western English Channel observatory. J Plankton Res 32: 585-601

Staal M, Meysman FJR, Stal LJ (2003) Temperature excludes N2-fixing heterocystous cyanobacteria in the tropical oceans. Nature 425:504-507

Thuiller W, Albert C, Araujo MB, Berry PM and others (2008) Predicting global change impacts on plant species' distributions: future challenges. Perspect Plant Ecol Evol Syst 9:137-152

Tilman D (1982) Resource competition and community structure. Princeton University Press, Princeton, NJ

Tilman D (1990) Constraints and tradeoffs: toward a predic- 
tive theory of competition and succession. Oikos 58:3-15

Tilman D, Kilham SS, Kilham P (1982) Phytoplankton community ecology: the role of limiting nutrients. Annu Rev Ecol Syst 13:349-372

Urban MC, De Meester L, Vellend M, Stoks R, Vanoverbeke J (2012) A crucial step toward realism: responses to climate change from an evolving metacommunity perspective. Evol Appl 5:154-167

Van Doorslaer W, Stoks R, Swillen I, Feuchtmayr H, Atkinson D, Moss B, De Meester L (2010) Experimental thermal microevolution in community-embedded Daphnia populations. Clim Res 43:81-89

Webb CT, Hoeting JA, Ames GM, Pyne MI, Poff NL (2010) A structured and dynamic framework to advance traitsbased theory and prediction in ecology. Ecol Lett 13: 267-283

Widdicombe CE, Eloire D, Harbour D, Harris RP, Somerfield

Submitted: December 19, 2011; Accepted: June 29, 2012
PJ (2010) Long-term phytoplankton community dynamics in the western English Channel. J Plankton Res 32: 643-655

Wiens JA, Stralberg D, Jongsomjit D, Howell CA, Snyder MA (2009) Niches, models, and climate change: assessing the assumptions and uncertainties. Proc Natl Acad Sci USA 106:19729-19736

- Wirtz KW, Eckhardt B (1996) Effective variables in ecosystem models with an application to phytoplankton succession. Ecol Model 92:33-53

Wu Y, Gao K, Riebesell U (2010) $\mathrm{CO}_{2}$-induced seawater acidification affects physiological performance of the marine diatom Phaeodactylum tricornutum. Biogeosciences 7:2915-2923

Yoshida T, Jones LE, Ellner SP, Fussmann GF, Hairston NG (2003) Rapid evolution drives ecological dynamics in a predator-prey system. Nature 424:303-306

Proofs received from author(s): October 1, 2012 